\title{
Comparison of dynamic models of battery energy storage for frequency regulation in power system
}

DOI:

10.1109/MELCON.2016.7495314

\section{Document Version}

Accepted author manuscript

Link to publication record in Manchester Research Explorer

\section{Citation for published version (APA):}

Adrees, A., Andami, H., \& Milanovic, J. V. (2016). Comparison of dynamic models of battery energy storage for frequency regulation in power system. In Electrotechnical Conference (MELECON), 2016 18th Mediterranean https://doi.org/10.1109/MELCON.2016.7495314

\section{Published in:}

Electrotechnical Conference (MELECON), 2016 18th Mediterranean

\section{Citing this paper}

Please note that where the full-text provided on Manchester Research Explorer is the Author Accepted Manuscript or Proof version this may differ from the final Published version. If citing, it is advised that you check and use the publisher's definitive version.

\section{General rights}

Copyright and moral rights for the publications made accessible in the Research Explorer are retained by the authors and/or other copyright owners and it is a condition of accessing publications that users recognise and abide by the legal requirements associated with these rights.

\section{Takedown policy}

If you believe that this document breaches copyright please refer to the University of Manchester's Takedown Procedures [http://man.ac.uk/04Y6Bo] or contact uml.scholarlycommunications@manchester.ac.uk providing relevant details, so we can investigate your claim.

\section{OPEN ACCESS}




\title{
Comparison of Dynamic Models of Battery Energy Storage for Frequency Regulation in Power System
}

\author{
Atia Adrees, Member, IEEE, Hooman Andami, Member, IEEE, and Jovica V. Milanović, Fellow, IEEE
}

\begin{abstract}
The paper investigates the use of frequently discussed battery energy storage system (BESS) models for frequency regulation studies. Integration of a large number of renewable generation sources results in increased uncertainty in electric power generation, requiring, among the others, more frequency regulation services than before. The battery energy storage system models are compared and evaluated to assess their suitability for frequency regulation studies. The accuracy and complexity of BES models reported in the past are also discussed.
\end{abstract}

Index Terms-Battery energy storage systems, Load frequency control (LFC), Battery models

\section{INTRODUCTION}

$\mathrm{T}$ he operation of an electric power system is a complex process of forecasting the demand for electricity, and scheduling and operating a large number of power plants to meet that varying demand in real time. At every instant, electrical power generation should match power consumption to keep system frequency constant.

The integration of renewable energy sources reduces the dependence on fossil fuels and greenhouse gas emission but increases variability and uncertainty in electric power generation. It is estimated that for every $10 \%$ wind penetration, a balancing power from other generation sources equivalent to $2 \%$ to $4 \%$ of the installed wind capacity is required for a stable power system operation [1]. Thus, with more penetration of intermittent renewables, the power system operation will become more complex and will require additional balancing power. As a result of this, there have been serious concerns over the safe and reliable operation of power systems with large penetration of renewable sources and reduction in conventional generation.

Effective energy storage can match total generation to total load precisely on a second by second basis. Energy storage can facilitate load leveling for generators, load leveling for postponement of grid upgrade, frequency regulation, and power quality. Conventional generators may take several minutes or even hours to come online and will consume fuel

This research was partly supported by EPSRC-China collaborative project RESTORES and partly by EU FP7 project SuSTAINABLE.

Atia Adrees, H. Andami, and J.V. Milanovic' and are with the Department of Electrical Engineering, The University of Manchester, M139PL Manchester, UK(e-mail:atia.adrees@manchester.ac.uk, Hooman.andami@manchester.ac.uk; milanovic@manchester.ac.uk). even when providing a spinning reserve, i.e., when they are on standby.

There are a variety of energy storage options, each with unique operational performance, and durability characteristics. Rated capacity varies from I kW to $1 \mathrm{GW}$, and discharge time at rated capacity varies from seconds to hours. Similarly, the response time of available storage technologies varies from a few milliseconds to a few minutes [2].

Frequency regulation (transient and permanent grid frequency stability support) requires low and medium capacity energy storage devices with a response time of tens of seconds [1]. Batteries (lead-acid, NaS) flywheels, supercapacitors have been all deployed for frequency regulation [3].

Battery energy storage has received substantial attention and support as it offers acceptable cost and performance requirements, providing operating and sitting flexibility and possibly requiring short lead time for construction. BESS (battery energy storage system) over-performs conventional reserve suppliers since it can react and fully activate the reserve within $20 \mathrm{~ms}$ [2].

Many studies have been performed in the past to demonstrate the effectiveness of battery storage for frequency control, power regulation and spinning reserve [4-6]. There are numerous factors like battery type, charge, and discharge rate, temperature, and state of charge that might affect dynamic behavior of a battery. Consequently, many types of models have been proposed for BESS in the literature [7-10].

The paper reviews some of the most frequently used battery models and presents the first comparative analysis of these models - to assess their merits for application in frequency regulation studies. The models are compared in terms of their accuracy and requirement of data.

The obtained results demonstrate that the nonlinear battery model is more accurate than other battery models. However, the use of this model requires data from battery discharge curve which can be a demanding task. On the other hand, battery modelled as a voltage source considering the state of charge is simple and accurate enough for load frequency studies.

\section{DYNAMIC MODELS FOR BATTERY ENERGY STORAGE}

A battery energy storage system (BESS), usually consists of a battery bank and a power converter that interfaces the battery bank to the AC network. A variety of battery energy storage models exist. In this section, brief overviews of most 
commonly used BESS models are presented.

\section{A. Thevinen Model}

The first attempt to develop a dynamic model of a battery energy storage was made by Beck et al in 1976 [7, 8]. In this model, presented in Fig. 1, BES is represented by a voltage source in series with a parallel RC circuit. It is a simple way of demonstrating the behavior of battery voltage $\mathrm{V}_{\mathrm{b}}$. It contains electrical values of no-load voltage $V_{o c}$, internal resistance $R_{1}$ and overvoltage (parallel combination of $\mathrm{C}_{1}$ and $\mathrm{R}_{2}$ ).

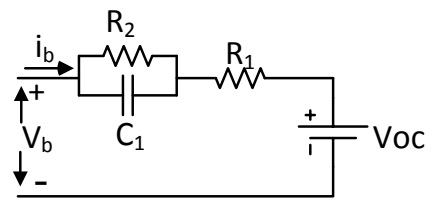

Fig. 1: Thevenin Model of Battery Energy Storage (adapted from [7])

Although this model can describe the outer behavior of a BES correctly, it is incomplete because values of $R_{1}, C_{1}$, and $\mathrm{R}_{2}$ are not constant as modeled. In fact, they are functions of various battery conditions such as state of charge, battery storage capacity, the rate of charge/discharge, environmental temperature, age/shelf life [8].

\section{B. Battery Equivalent Circuits}

Salameh et al presented a mathematical model in 1992 [8], presented in Fig. 2.

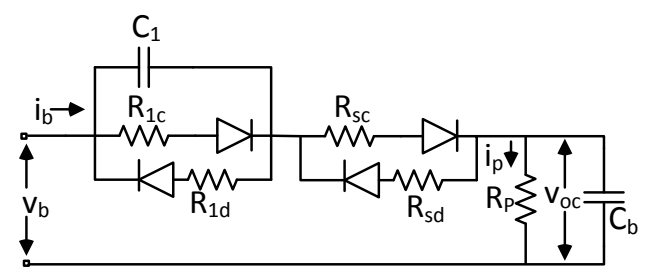

Fig. 2: Battery Equivalent Circuit (adapted from [8])

Where $\mathrm{C}_{1}$ is the overvoltage capacitance, $\mathrm{C}_{\mathrm{b}}$ the is battery capacity, $i_{b}$ the current source, $i_{p}$ the parallel current, $R_{i c}$ and $R_{\text {id }}$ charge and discharge overvoltage resistance, $R_{p}$ the selfdischarge resistance, $R_{s c}$ and $R_{s d}$ are internal resistance for charge and discharge, $\mathrm{V}_{\mathrm{b}}$ is the battery voltage, and $\mathrm{V}_{\mathrm{oc}}$ is open circuit voltage.

This model was developed using nonlinear elements and allows a continuous evaluation of battery performance $[8,11]$. The model components were found using manufacturing specifications and experimental tests. The model takes into account self-discharge, battery storage capacity, internal resistance, overvoltage and environmental temperature.

\section{1) BES Equivalent Circuits with Converter}

In 1995, Liu et al combined characteristics of battery equivalent circuits and converter to construct a dynamic model of BES [9].

To enable the BES model to be easily utilized in stability analysis of a power system, the model was also presented in frequency domain, shown in Fig. 3.

Where $V_{t}$ is the BES terminal voltage, $E_{D O}$ is ideal no-load DC voltage of the converter, $X_{\mathrm{co}}$ is the commutating resistance of the converter, $R_{B T}$ and $R_{B S}$ are the battery connecting resistance and internal resistance, $\mathrm{R}_{\mathrm{B} 1}$ and $\mathrm{C}_{\mathrm{B} 1}$ are resistance and capacitance at charging and discharging, $\mathrm{C}_{\mathrm{BP}}$ is the battery capacitance.

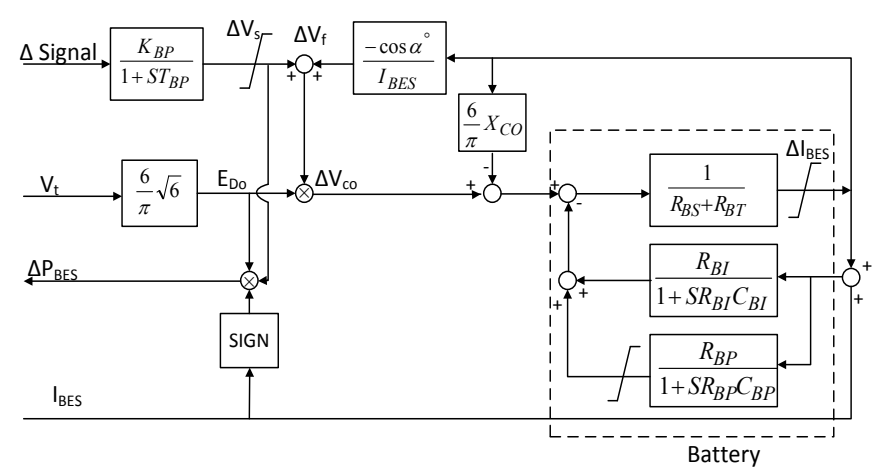

Fig. 3: Dynamic Model of (battery equivalent circuits) BES (adopted from [9])

\section{2) Incremental BES Model}

Later in 1999, Aditya et al [10] proposed an incremental BES model that is based on battery equivalent circuits. It is very similar to the model proposed by Liu et al. The only difference is a terminal voltage of the battery is not considered as an input signal in this model.

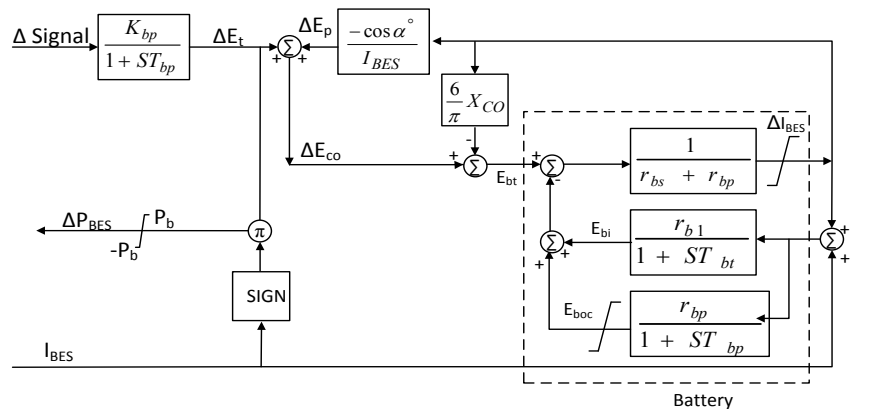

Fig. 4: Incremental BES Model (adapted from [10])

This model has been widely used for load frequency control studies $[12,13]$.

Although constant current control operating mode is most efficient for a BES, in load frequency control, the BES is operated in constant power mode [14]. After linearization, small change in power of the BES can be written as

$$
\begin{gathered}
\Delta P_{B E S}=V_{c o}^{0} \Delta I_{B E S}+I_{B E S}^{0} \Delta V_{c o} \\
\text { Where } V_{c o}=E_{D O} \cos \alpha
\end{gathered}
$$

$\Delta V_{c o}$ can be decomposed into two components (a) $E_{D O} \Delta V_{f}$ corresponding to power deviation caused by $\triangle I_{B E S}$ and (b) $E_{D O}$ $\Delta V_{s}$ corresponding to the system disturbance.

$$
\Delta P_{B E S}=V_{c o}^{0} \Delta I_{B E S}+I_{B E S}^{0} E_{D O}\left(\Delta V_{f}+\Delta V_{s}\right)
$$

and

$$
\begin{gathered}
\Delta P_{B E S}=I_{B E S}^{0} E_{D O} \Delta V_{s} \\
\text { When } \quad \Delta V_{f}=\frac{-\cos \alpha^{0}}{I_{B E S}^{0}} \Delta I_{B E S} \\
\text { Where } \quad \Delta V_{s}=\frac{K_{B P}}{1+S T_{B P}} \Delta \text { Signal }
\end{gathered}
$$


Where $K_{B P}$ and $T_{B P}$ are control loop gain and measurement device time constant respectively. From (4) and (6) it can be deduced that output of a battery is a function of voltage and change in the feedback signal. The feedback signal is a change in frequency in load frequency control (LFC) studies. This reduces the incremental BES model and BES equivalent circuits model to a simple first-order lag model when voltage $\mathrm{E}_{\mathrm{DO}}$ is considered constant. It is to be noted that in LFC studies it is a general practice to consider voltage a constant.

\section{Non-Linear Battery Model}

Shephard developed an equation to describe the electrochemical behavior of a battery directly in terms of its terminal voltage, open circuit voltage, internal resistance, discharge current and state of charge in 1965 [15]. The model based on this equation represents charged and discharged characteristics of a battery. However, it generates an algebraic loop problem in closed-loop simulations of modular models [16].

In 2007, a non-linear battery model was proposed in [16], shown in Fig. 5. This simulation model uses only battery state of charge (SOC) as a state variable to avoid algebraic loop problem. In this model, the internal voltage of the battery is not fixed and is dependent on charging or discharging current.

Where $\mathrm{E}$ is no-load voltage, $\mathrm{E}_{0}$ is battery constant voltage, $K$ is polarization voltage, $Q$ is battery capacity, $I$ is Battery current, $A$ is exponential zone amplitude, $B$ is exponential zone time constant inverse and $\int \mathrm{idt}=$ actual battery charge .

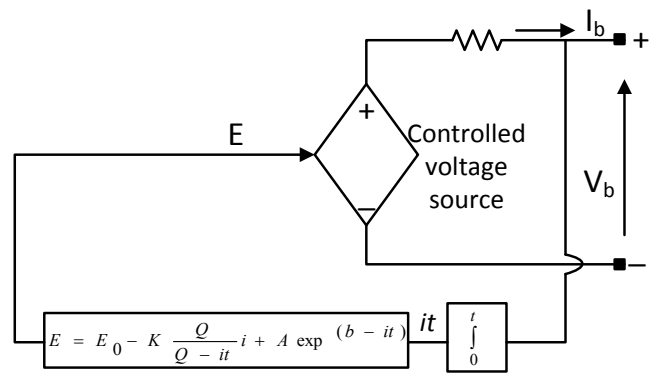

Fig. 5: Non-Linear Battery Model (adapted from [16])

This model can accurately represent the behavior of many battery types. The parameters can be deduced from manufacturer's discharge curve [17].

\section{DC Voltage Source in Series with a Resistor}

Studies presented in $[18,19]$ modeled the battery energy storage as a DC voltage source in series with a current controlled inverter (CCI) in an islanded microgrid.

The state of charge for charging and discharging of a battery, in addition, to the $\mathrm{DC}$ voltage source in series with an inverter is modeled in [20-22]. All these studies dealt with frequency stability in micro-grid systems.

\section{1) First order Lag model}

Simplification of battery model to a first order system has been preferred in many studies [23-26].

Using this simplified model, the effect of a battery energy storage system, which can supply $30 \mathrm{MW}$ for 15 minutes, on frequency control in Israel Electric Corporation is studied.
Performed analysis indicated that battery energy storage can dramatically reduce (6 times less) frequency fluctuations resulting from sudden demand variations [23].

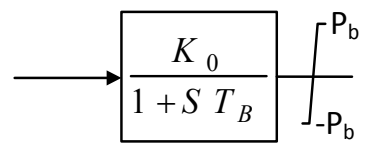

Fig. 6: First Order Model

Redox flow battery (RFB) was modeled in [26, 27] by first order model. It is shown that RFB unit suppresses peak frequency deviations and continue to eliminate steady state error of frequency deviations.

\section{2) First order model with state of the charge}

First order model with state of charge, presented in Fig. 7 has been used in many studies [28-32].

An optimized scheduling of a hybrid wind-diesel system with a BES in an isolated power system has been presented in [28] using first order model of a battery with the state of charge.

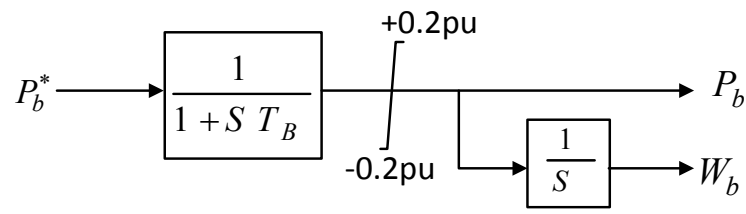

Fig. 7: First Order Model with State of Charge (adopted from [28]

A load frequency control method in wind power generation with a battery storage system is proposed in [30], and battery storage system is represented by the first-order model with state of charge. The method adjusts output of BES according to present state of the charge and applies $H_{\infty}$ control to generator controller to achieve robust control considering parameters fluctuations generated by state variations in the power system.

\section{TEST SYSTEM}

The effect of different battery energy storage system models on LFC studies is investigated in an isolated $2 \mathrm{GW}$ classic power system with reheat thermal unit. The transfer function model of the classical system is presented in Fig. 8. The capacity of battery energy storage system considered in these studies is $1.15 \mathrm{MWh}$, and it is assumed that BES can provide a maximum power output of $90 \mathrm{MW}$ for 46 seconds. The simulations are performed in Matlab/Simulink.

The frequency response of the classical system with each battery model, discussed in Section II, with five cascaded disturbances is simulated. Each of these disturbances is a 0.05 p.u increase in the load. Table I presents parameters of the system.

A variety of controls for battery energy storage has been proposed in the literature $[22,31]$. Since the aim of this paper is to demonstrate the effect of different battery storage models on load frequency studies, proportional control is used with BES system. The use of PI controller makes the BES contribute in load leveling. 


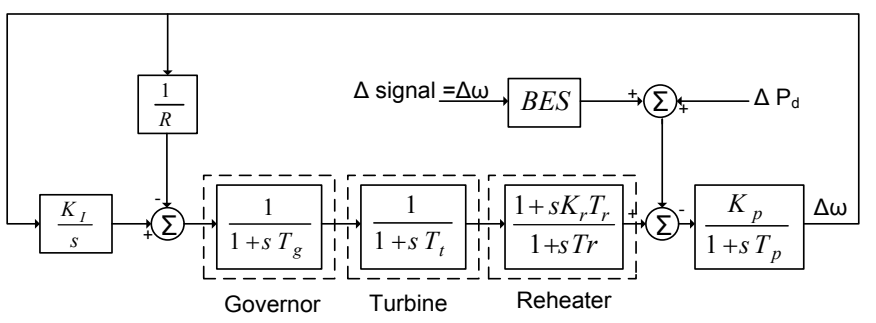

Fig. 8: Transfer function model of a classical system

Table I: Parameters of the classical system

\begin{tabular}{clcl}
\hline Parameter & Value & Parameter & Value \\
\hline$K_{p}$ & 120 & $T_{t}$ & 0.3 \\
\hline$T_{p}$ & 20 & $T_{r}$ & 10 \\
\hline $\mathrm{D}$ & 1 & $K_{r}$ & 0.5 \\
\hline$K_{t}$ & 1 & $R$ & 2 \\
\hline
\end{tabular}

\section{RESULTS AND DISCUSSIONS}

1) Thevenin Model versus Voltage Source in Series with a Resistor

First, the battery energy storage system is represented by Thevenin model and five cascaded disturbances in the load are introduced. The system frequency response to these variations in load is shown by the red line in Fig. 9.

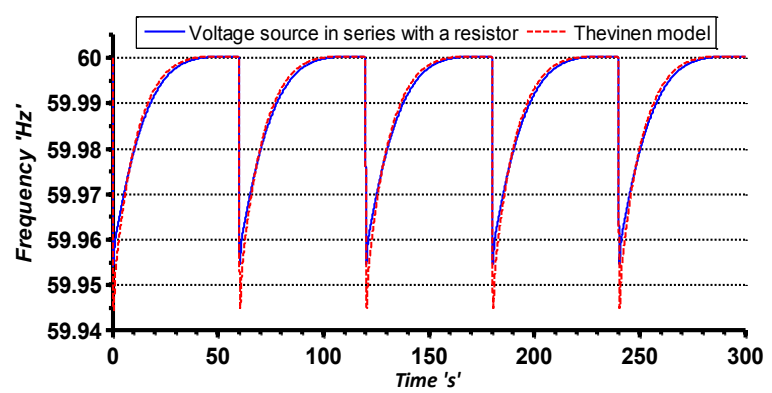

Fig. 9: Comparison of Thevenin model and voltage source in series with a resistor

Following this, BES model is replaced by a voltage source in series with a resistor. Same five cascaded disturbances in the load are applied, and frequency response of the system is recorded, presented in Fig. 9.

It can be observed that with both types of BES models, the trajectory followed by system frequency is very similar, except the first dip in system frequency when the disturbance is introduced in the system. The dip in frequency with Thevenin model is slightly bigger than voltage source in series with a resistor.

\section{2) Battery Equivalent Circuits versus Voltage Source in} Series with a Resistor

The frequency response of the system with equivalent circuits model and voltage source in series with a resistor is presented in Fig. 10. Blue curve shows the system frequency when BES is modeled with a voltage source in series with a resistor, and the red curve represents the frequency of the system when BES is represented by battery equivalent circuits.
It can be observed that the difference in system frequency response due to different battery models becomes more noticeable as the number of disturbance increases. Battery equivalent circuits model takes into consideration the energy stored in the battery, as the stored energy decreases battery provides less power (see Fig. 11) increasing the dip in system frequency. After every disturbance, the response of the system with equivalent circuit model becomes more similar to the system without battery, i.e., bigger dips in the system frequency. The frequency support of BES decreases after each disturbance as the stored energy in the battery reduces.

It is to be noted that the control system of the battery is modeled with a proportional controller while the system without battery has an integral control in the secondary loop.

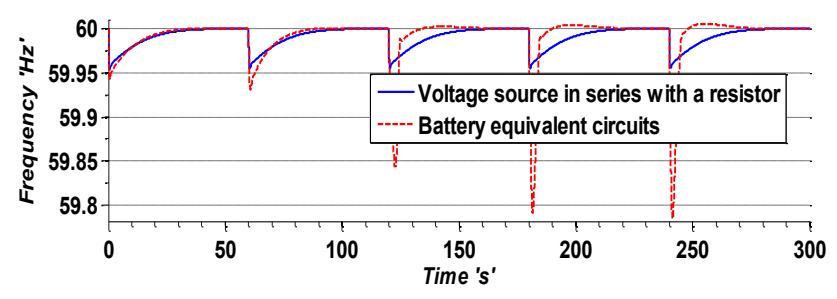

Fig. 10: Comparison of battery equivalent circuits model and voltage source in series with a resistor

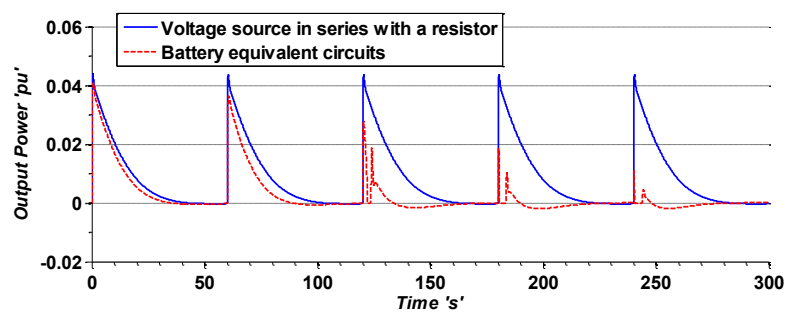

Fig. 11: Power supplied by battery equivalent model and voltage source in series with a resistor

\section{3) Incremental Model}

As explained in the previous section both BES models, incremental and battery equivalent circuits reduce to the same model in LFC studies. Simulations results with battery equivalent circuits model are presented in the previous section that eliminates the need to simulate the incremental model.

4) Non-Linear Model versus Voltage Source in Series with a Resistor

Fig. 12 compares the system frequency response when BES is represented by a non-linear model (red curve) and by a voltage source in series with a resistor (blue curve). It is evident from the figure that following the first disturbance, system frequency behavior with both types of model is nearly identical. After the second and third disturbance, there is a slight difference in the frequency dip, and fifth disturbance leads to a much bigger dip in system frequency if the nonlinear model of battery is used.

Similar to battery equivalent circuits, the difference between the non-linear BES model and voltage source in series with a resistor model becomes more visible when the stored energy in the battery is reduced. 


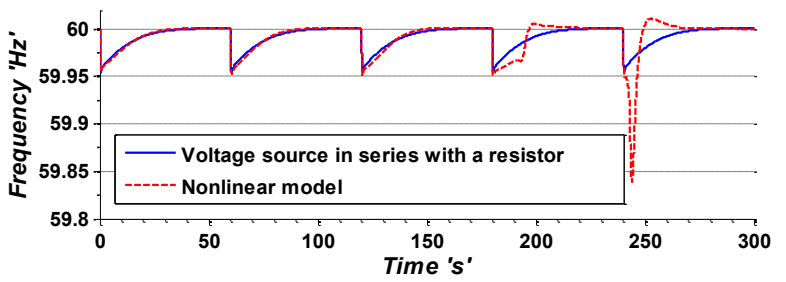

Fig. 12: Comparison of non-linear model and voltage source in series with a resistor

\section{5) First-order Model versus Voltage Source in Series with} a Resistor

It is standard practice to a model voltage source with a resistor as a first order model in LFC studies. Hence, first order model is not simulated in these studies.

6) First order Model with state of charge versus Voltage Source in Series with a Resistor

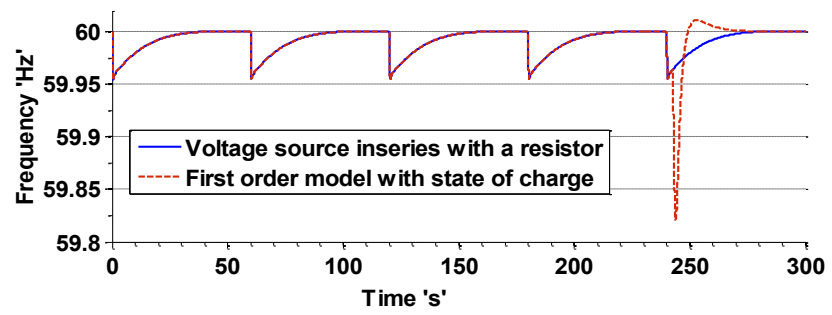

Fig. 13: Comparison first order model with state of charge and voltage source in series with a resistor

Fig. 13 compares the response of system frequency when BES is represented by the first order model with state of charge, and a voltage source in series with a resistor. In first order model with state of charge, the power produced by the battery is not a function of charge (the power provided by the BES stays constant). However, when all the stored energy is consumed, the output power of the battery is reduced to zero.

It can be observed that the frequency response of the system is identical with both types of BES models. The difference in the response (at 250s time stamp) only appears when the battery is fully discharged.

The output power of the battery depends on charging and discharging currents. For a better understanding of the dynamic behavior of different battery models, the output power of discussed models under the same discharging current have been shown in Fig. 14.

Fig. 14a demonstrates that the battery models can be grouped into two categories:

Group 1: Voltage source in series with a resistor, Thevenin model and first order model with state of charge.

\section{Group 2: Nonlinear model and battery equivalent circuits}

In group 1 the power outputs of the voltage source in series with a resistor and first order model with state of charge are the same until the stored energy is consumed. It can also be observed that power output of Thevenin model follows power output of voltage source in series with a resistor closely.

The power output of group 2 models differs significantly from group 1 models, this difference in the output power increases with the discharge of the battery. It can also be noticed that the power output of battery equivalent circuits starts to deviate from power output of the nonlinear model, and this deviation increases with time.

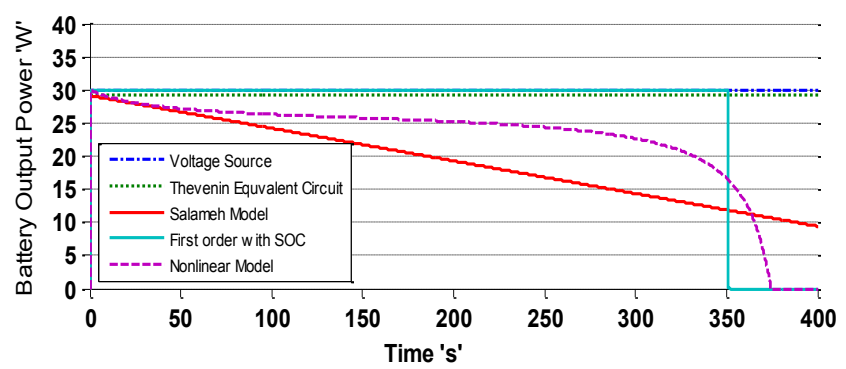

Fig. 14a: Output power for different battery models when they have been discharged by a constant $30 \mathrm{~A}$ current.

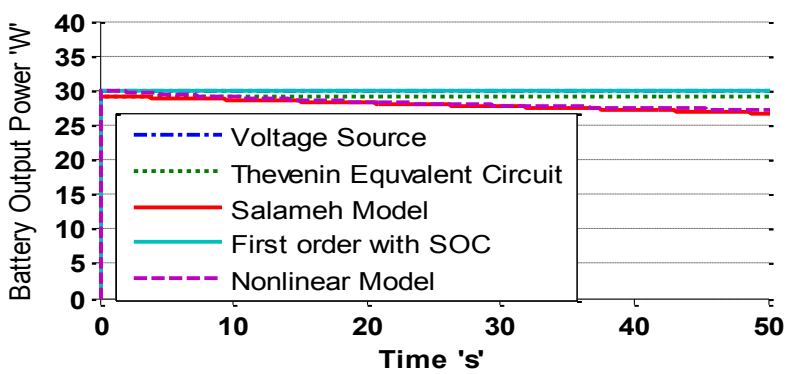

Fig. 14b: Output power for different battery models when they have been discharged by a constant $30 \mathrm{~A}$ current.

Focusing more closely, Fig. 14b shows that different battery models have a very similar response in first 20 seconds after the disturbance, the power output of different battery models is nearly same. After 20 seconds, the output power of group 2 models starts to differ from group 1 models and at 50 seconds $10 \%$ reduces it compared to the output power of group 1 models. Primary frequency control is normally within the 20$50 \mathrm{sec}$ time scale, and in the case of fully charged battery, it would be difficult to see any significant difference in the response of different battery models.

\section{CONCLUSION}

This paper presented the first comparative analysis of the most commonly used battery energy storage system models to assess their suitability for load frequency control studies. These comparative studies are performed using a simple small power system model. It is observed that frequency response of the system with different BES models is similar after the first disturbance. The frequency response of the system with battery equivalent circuits shows bigger frequency dip after first disturbance, and the depth of the dip becomes bigger after each disturbance. Non-linear battery model and first order model with state of charge follows closely the frequency response trajectory of the voltage source in series with a resistor model until the battery is discharged.

Based on these studies, it can be concluded that the most important battery parameters that can significantly affect LFC studies is the state of the charge. Other parameters like charging or discharging process, internal resistance and temperature dependency or converter model do not have any appreciable effect on LFC studies. The dynamics of frequency 


\section{ACCEPTED VERSION OF THE PAPER}

regulation is slow so that it does not require detailed modeling of fast dynamic processes in the battery.

The nonlinear battery model is more accurate,however, it could be challenging to obtain required battery data from discharge curve.

Simple voltage source considering the state of charge is simple and accurate enough for load frequency studies.

\section{REFERENCES}

[1] S. Vazquez, S. M. Lukic, E. Galvan, L. G. Franquelo, and J. M. Carrasco, "Energy Storage Systems for Transport and Grid Applications," IEEE Transactions on Industrial Electronics, vol. 57, pp. 3881-3895, 2010.

[2] H. Ibrahim, A. Ilinca, and J. Perron, "Energy storage systemsCharacteristics and comparisons," Renewable and Sustainable Energy Reviews, vol. 12, pp. 1221-1250, 2008.

[3] Helder Lopes Ferreira, Raquel Garde, Gianluca Fulli, Wil Kling, and Joao Pecas Lopes, "Characterisation of electrical energy storage technologies," Energy, vol. 53, pp. 288-298, 2013.

[4] George D Rodriguez, William C Spindler, and DS Carr, "Operating the world's largest lead/acid battery energy storage system," Journal of power sources, vol. 31, pp. 311-320, 1990.

[5] F. A. Bhuiyan and A. Yazdani, "Energy storage technologies for grid-connected and off-grid power system applications," in IEEE Electrical Power and Energy Conference (EPEC), 2012, 2012, pp. 303-310.

[6] D. D. Banham-Hall, G. A. Taylor, C. A. Smith, and M. R. Irving, "Frequency control using Vanadium redox flow batteries on wind farms," in IEEE Power and Energy Society General Meeting, 2011, 2011, pp. 1-8.

[7] J. W. Beck, D. P. Carroll, G. E. Gareis, P. C. Krause, and C. M. Ong, "A computer study of battery energy storage and power conversion equipment operation," Power Apparatus and Systems, IEEE Transactions on, vol. 95, pp. 1064-1072, 1976.

[8] Z. M. Salameh, M. A. Casacca, and William A. Lynch, "A mathematical model for lead-acid batteries," IEEE Transactions on Energy Conversion, vol. 7, pp. 93-98, 1992.

[9] C. F. Lu, C. C. Liu, and C. J. Wu, "Dynamic modelling of battery energy storage system and application to power system stability," IEE Proceedings- Generation, Transmission and Distribution, vol. 142, pp. 429-435, 1995.

[10] S. K. Aditya and D. Das, "Application of battery energy storage system to load frequency control of an isolated power system," International Journal of Energy Research, vol. 23, pp. 247-258, 1999.

[11] M. A. Casacca and Z. M. Salameh, "Determination of lead-acid battery capacity via mathematical modeling techniques," IEEE Transactions on Energy Conversion, vol. 7, pp. 442-446, 1992.

[12] S. K. Aditya and D. Das, "Load-frequency control of an interconnected hydro-thermal power system with new area control error considering battery energy storage facility," International Journal of Energy Research, vol. 24, pp. 525-538, 2000.

[13] S. K. Aditya and D. Das, "Battery energy storage for load frequency control of an interconnected power system," Electric Power Systems Research, vol. 58, pp. 179-185, 2001.

[14] Lu Chun-Feng, Liu Chun-Chang, and Wu Chi-Jui, "Effect of battery energy storage system on load frequency control considering governor deadband and generation rate constraint," IEEE Transactions on Energy Conversion, vol. 10, pp. 555-561, 1995.

[15] C.M.Shepherd, "Design of Primary and Secondary Cells- part II. An Equation Describing Battery Discharge " Journal of The Electrochemical Society, vol. 112, pp. 657-664, 1965.

[16] O. Tremblay, L. A. Dessaint, and A. I. Dekkiche, "A Generic Battery Model for the Dynamic Simulation of Hybrid Electric Vehicles," in IEEE Vehicle Power and Propulsion Conference, 2007. VPPC 2007., 2007, pp. 284-289.

[17] O. Tremblay, L. A. Dessaint, and A. I. Dekkiche, "A Generic Battery Model for the Dynamic Simulation of Hybrid Electric Vehicles," in Vehicle Power and Propulsion Conference, 2007. VPPC 2007. IEEE, 2007, pp. 284-289.
R. Sebastián, "Smooth transition from wind only to wind diesel mode in an autonomous wind diesel system with a battery-based energy storage system," Renewable Energy, vol. 33, pp. 454-466, 2008.

[19] R. Sebastián and J. Quesada, "Distributed control system for frequency control in a isolated wind system," Renewable Energy, vol. 31, pp. 285-305, 2006.

[20] I. Serban and C. Marinescu, "A solution for frequency control in islanded three-phase micro-grids supplied by Renewable Energy Sources," in 11th International Conference on Optimization of Electrical and Electronic Equipment, 2008. OPTIM 2008. , 2008, pp. 327-332.

[21] I. Serban, R. Teodorescu, and C. Marinescu, "Analysis and optimization of the battery energy storage systems for frequency control in autonomous microgrids, by means of hardware-in-theloop simulations," in 3rd IEEE International Symposium on Power Electronics for Distributed Generation Systems (PEDG), 2012, 2012, pp. 374-379.

[22] Mohammad Reza Aghamohammadi and Hajar Abdolahinia, "A new approach for optimal sizing of battery energy storage system for primary frequency control of islanded Microgrid," International Journal of Electrical Power \& Energy Systems, vol. 54, pp. 325-333, 2014.

[23] D. Kottick, M. Blau, and D. Edelstein, "Battery energy storage for frequency regulation in an island power system," IEEE Transactions on Energy Conversion, vol. 8, pp. 455-459, 1993.

[24] Daniel Kottick and Moshe Blau, "Operational and economic benefits of battery energy storage plants," International Journal of Electrical Power \& Energy Systems, vol. 15, pp. 345-349, 1993.

[25] Dulal Ch Das, A. K. Roy, and N. Sinha, "GA based frequency controller for solar thermal-diesel-wind hybrid energy generation/energy storage system," International Journal of Electrical Power \& Energy Systems, vol. 43, pp. 262-279, 2012.

[26] I. A. Chidambaram and B. Paramasivam, "Control performance standards based load-frequency controller considering redox flow batteries coordinate with interline power flow controller," Journal of power sources, vol. 219, pp. 292-304, 2012.

[27] I. A. Chidambaram and B. Paramasivam, "Optimized loadfrequency simulation in restructured power system with Redox Flow Batteries and Interline Power Flow Controller," International Journal of Electrical Power \& Energy Systems, vol. 50, pp. 9-24, 2013.

[28] E. Abbasi, H. Ameli, K. Strunz, and N. H. Duc, "Optimized operation, planning, and frequency control of hybrid generationstorage systems in isolated networks," in Innovative Smart Grid Technologies (ISGT Europe), 2012 3rd IEEE PES International Conference and Exhibition on, 2012, pp. 1-8.

[29] Abdul Motin Howlader, Yuya Izumi, Akie Uehara, Naomitsu Urasaki, Tomonobu Senjyu, Atsushi Yona, and Ahmed Yousuf Saber, "A minimal order observer based frequency control strategy for an integrated wind-battery-diesel power system," Energy, vol. 46, pp. 168-178, 2012.

[30] M. Toge, Yu Kurita, and S. Iwamoto, "Supplementary load frequency control with storage battery operation considering SOC under large-scale wind power penetration," in IEEE Power and Energy Society General Meeting (PES), 2013, 2013, pp. 1-5.

[31] Ono.T and J. Arai, "Frequency control with dead band characteristic of battery energy storage system for power system including large amount of wind power generation," Electrical Engineering in Japan, vol. 185, pp. 709-717, 2013.

[32] K. Hongesombut, T. Piroon, and Y. Weerakamaeng, "Evaluation of battery energy storage system for frequency control in microgrid system," in 10th International Conference on Electrical Engineering/Electronics, Computer, Telecommunications and Information Technology (ECTI-CON), 2013 2013, pp. 1-4. 